\title{
LINHAS FILOSÓFICAS E IDEOLÓGICAS NA PESQUISA EM ENFERMAGEM NO BRASIL *
}

Semiramis Melani Melo Rocha** Graciete Borges da Silva***

\begin{abstract}
RESUMO - O trabalho se propõe a uma análise do processo de produção da pesquisa em enfermagem no Brasil, tendo por fonte básica de dados os catálogos de teses publicados pelo Centro de Estudos e Pesquisas em Enfermagem (CEPEn). Possui uma parte introdutória, onde são apresentadas as principais correntes filosóficas que embasam os diversos métodos científicos de interpretação, existentes na área da saúde e onde se discute o conceito de ideologia. Esta introdução fundamenta a discussão central referente às características filosófico-ideológicas da citada produção da enfermagem brasileira. Os resultados encontrados mostram que essa produção vincula-se, de maneira genérica, ao positivismo.
\end{abstract}

\begin{abstract}
This essay deals with an analysis of the process of production of the research on nursing in Brazil, having as basic source of data the catalogues of theses published by the Center of Studies and Researches on Nursing (Centro de Estudos e Pesquisas em Enfermagem - (CEPEn). It has an introductory part, were the main philosophical currents are shown. These currents serve as basis for the several scientific methods of interpretation, existent in the area of health and were the concept of ideology is discussed. That introduction establishes the central discussion referring to the philosophicalideological characteristics of the above mentioned production of the Brazilian nursing. The results that were found showed that this production is linked, in a generic way, to the positivism.
\end{abstract}

\section{INTRODUC̣ÃO}

A primeira questão que se impõe a um investigador é a delimitação de seu objeto de estudo. Em um trabalho de pesquisa, em geral, as primeiras considerações procuram caracterizar o objeto e o conjunto de procedimentos lógicos e técnicos a serem utilizados (métodos), que se articulam a uma determinada teoria ou paradigma explicativo de uma realidade. Assim, todo conhecimento científico pressupõe uma especulação filosófica sobre a problemática de seus determinantes, porque existe um hiato entre o objeto da investigação e as possíveis represetações dele. Ou seja, o ser humano, agente do conhecimento,

“além de ser biológico, é um 'dispositivo teórico-social'. Isto quer dizer, em termos mais simples, que sua percepção da realidade não está apenas condicionada pelas qualidades intrínsecas e limitações de sua sensibilidade enquanto organismo biológico, mas também é determinada pela 'perspectiva' a partir da qual a sociedade de que é membro contempla o 'mundo' (a ciência é apenas um e nem sempre principal elemento dessa perspectiva), em cujos termos foi socializado e se formou como ser pensante" (SANTOS, 1984).

Em outras palavras, para que a realidade se torne inteligível e seja conhecida deve ser estruturada e ordenada pelo homem segundo sua "visão de mundo". As considerações feitas até aqui sugerem a importãn-

\footnotetext{
* Conferência proferida na 37ª Reunião Anual da Sociedade Brasileira para o Progresso da Ciência. Belo Horizonte-MG, 1985.

** Professor Assistente Doutor do Departamento da Enfermagem Materno-Infantil e Saúde Pública da Escola de Enfermagem de Ribeirão Preto-USP.

${ }^{* * *}$ Professor Assistente Doutor junto ao Departamento de Enfermagem Psiquiátrica e Ciências Humanas da Escola de Enfermagem de Ribeirão Preto da Universidade de São Paulo.
} 
cia de se refletir sobre o processo do conhecimento. Qual a origem dos elementos que o estruturam? Como julgar a adequação do conhecimento ao objeto? Qual a confiabilidade desse conhecimento?

Estas questões têm sido debatidas ao longo da história do pensamento filosófico, estando sujeitas a controvérsias de diferentes correntes em uma mesma época.

A Filosofia Antiga ou Grega lançou as bases lógicas da ciência moderna, destacando-se em sua produção o período clássico (século V e IV a.C.) Para Aristóteles (384-322 a.C.), o conhecimento deveria ser dedutivo sendo que o silogismo constituiria a representação máxima do mecanismo de dedução. Partindo dos dados sensíveis e das opiniões comuns atinge-se um conteúdo geral, do qual pode-se extrair outros conhecimentos. Na filosofia aristotélica, portanto, o dado sensível (sensação e percepção) possui uma importância muito grande na fundamentação do conhecimento, cujo trajeto inicial consiste quase que num processamento do sensível (SILVA, 1980). É exatamente este aspecto que Descartes (1596-1650) vai contestar em fins do Renascimento. Seguindo o pensamento de Galileu Galilei (1564-1642), Descartes propõe um método para bem conduzir a razão e procurar a verdade nas ciências. Para ele, não é impossível compatibilizar o rigor desejável no conhecimento com as flutuações, os erros, as ilusões e as ambigüidades do contato imediato com o mundo sensível (SILVA, 1980). Para que se atinja um saber definitivo e absoluto é necessário um método que se inspire no rigor da demonstração matemática. 0 que temos de verdadeiro em si, primeiramente, são as idéias ou representações enquanto conteúdos "puros" da mente ou da alma. A introdução do paradigma matemático consiste em partir das idéias inatas com que o Criador nos dotou para fundamentar a aquisição da verdade. 0 pensamento cartesiano teve continuidade através do idealismo de Kant, Hegel, Spinoza e Leibniz.

0 primeiro filósofo idealista dos tempos modernos foi Emmanuel Kant (1724-1804), que se inspirou no debate travado entre o idealismo cartesiano e o empirismo defendido por Locke e David Hume (1711-1776) entre outros. Para Kant, o que Descartes entendia como idéias inatas são formas ou funções "a priori" do entendimento, isto é, preexistem a toda experiência sensível. Porém, para a transformação destas regras em conhecimento era necessário que o seu conteúdo fosse recolhido pelas sensações e percepções. 0 conhecimento teria assim dupla origem: uma "a priori" ou puramente lógica, constituída pelas categorias sintetizadoras do próprio entendimento; outra, "a posteriori" ou sensível, constituída pela "sensação e percepção". Exemplificando: fora de mim existem seres, pessoas, coisas; este universo é veiculado para o meu intelecto por meio dos sentidos; meu intelecto, através de categorias (noções de espaço, tempo, etc) coloca estas sensações e informações, de forma a dar a cada coisa um nome e colocá-la no espaço e no tempo definidos, a fim de ser por mim conhecido (OLIVEIRA et alii, 1981). A partir desta confirmação simultânea do empirismo e do racionalismo, várias correntes constituíram-se: $0 \mathrm{em}$ pirismo, que atribui o papel principal aos elementos sensoriais do conhecimento; o racionalismo aos elementos lógicos do conhecer e o irracionalismo às camadas profundas da consciência como emoções e as vivências (GARCIA, 1983).

Como corrente filosófica do século XIX, o Positivismo evoca a convicção de Augusto Comte (1798-1857) de que o nascimento da ciência teria marcado o início histórico da maturidade humana (CUPANI, 1984). Partindo do princípio de que o objeto da ciência é só o fato positivo, isto é, ocorrências empiricamente verificáveis, sujeitas ao método da observação e experimentação, Comte só reconhece as ciências experimentais ou positivas, que tratam dos fatos e suas leis (relações constantes entre fatos). Nega as construções apriorísticas e as questões transcendentes à experiência.

0 positivismo considera a ciência como único conhecimento válido da realidade; defende a unidade metodológica da ciência, estendendo a metodologia das ciências naturais ao campo das ciências humanas, embora admitindo a variedade das técnicas de pesquisa. Defende o controle intersubjetivo com a pretensão de garantir a imparcialidade ou neutralidade do pesquisador e o caráter realmente objetivo do conhecimento. Na concepção positivista, a linguagem científica deve ser precisa, unívoca e objetiva, despida de conotações subjetivas. Finalmente, essa corrente filosófica tende a privilegiar os aspectos quantitativos da experiência, por facilitar o controle inter-subjetivo e a objetividade dos dados.

0 neopositivismo. (ou positivismo lógico) reitera a posição empirista, já característica do positivismo, inovando com a introdução da Lógica Matemática como instrumento de análise da linguagem humana (CUPANI, 1984; BUNGE, 1980). Tem sua origem no denominado "Círculo de Viena", grupo de pensadores composto por matemáticos, lógicos, filósofos, historiadores, cientistas naturais e sociais. Pertenceram a ele Moritz Schlick (1882-1936), Rudolf Carnap (1891-1970) entre outros e, indiretamente, Karl Popper.

Apesar de sua breve atividade (década de 20 e 30) atuou de forma intensa e influente em nosso século, submetendo a duras críticas os neokantianos, existencialistas e materialistas dialéticos.

Quanto ao marxismo, constitui uma síntese metamorfoseada do idealismo alemão (Hegel), da economia política inglesa (Adam Smith e David Ricardo) e do socialismo utópico francês (Saint-Simon e Proudhon), (GARAUDY, 1967).

K. Marx (1818-1883) e F. Engels (1820-1895) utilizaram a lógica dialética para analisar, principalmente, os fatos sociais, econõmicos e políticos da sociedade européia do século XIX. Da filosofia hegeliana conservaram o conceito de dialética como movimento interno de produção da realidade, cujo motor é a contradi- 
ção. Marx demonstra, porém, que a contradição não é a do Espírito consigo mesmo, entre sua face subjetiva e sua face objetiva; entre sua exteriorização em idéias, como coloca Hegel, mas visualiza-a estabelecendo-se entre homens reais em condições históricas e sociais concretas, das quais a luta de classes seria um dos importantes exemplos.

A lógica dialética procura superar a questão colocada pela filosofia pré-hegeliana que distingue, no conhecimento, dois aspectos: de um lado, a experiência, o sensível, o imediato; de outro, a abstração, a forma, o raciocínio.

"O conhecimento, portanto, provém da experiência (o que havia sido reconhecido pelo empirismo clássico). Mas nem por isso ele deixa de constituir, em seu resumo lógico, uma razão; isso ocorre, porém, ao preço de um esforço imenso, secular, de dominação prática da natureza, de abstração, de reflexão, de tomada de consciência. Mediante este esforço, o pensamento se constituiu, se estabeleceu em determinado plano; em torno dele e nele mesmo, o pensamento descobre o racional unido ao real: o universal (concreto).

A experiência, portanto, não é feita de sensações individuais justapostas, como acreditava o empirismo clássico. Por outro lado, a razão não manifesta no homem uma atividade abstrata 'a priori' (metafisicamente anterior a experiência), proveniente de uma realidade misteriosa, Espírito transcendente ou Deus" (LEFEBVRE, 1983).

A razão é, portanto, o pensamento que descobre o racional unido ao real:

"Considerar alguma coisa racionalmente não é trazer de fora uma razão ao objeto...

A única tarefa da consciência é trazer à consciência (tornar consciente) esse trabalho próprio da razão da coisa" (CORBISIER, 1981).

Se tem sido problemático para o homem conhecer a natureza e apreendê-la em sua realidade, conhecer a natureza humana enredada em uma trama de relações sociais tem sido um debate constante entre as diversas áreas das ciências sociais.

Edmund Husserl (1859-1938), em fins do século XIX, opõe-se à tendência predominante na psicologia, que procura explicar o processo do conhecimento através do naturalismo, isto é, exatamente como os cientistas da natureza tratam os fenõmenos naturais. Formula, então, o método fenomenológico, dando origem a um movimento cuja influência estende-se, em nosso século, a todas as áreas das ciências humanas.

Para HUSSERL (1980), a objetividade, problema central da teoria do conhecimento, não pode ser alcançada através do naturalismo, do qual o psicologismo é parte, anulando-se a dif erença entre sujeito e objeto, e afirmando que a única realidade é a Natureza. Procura desfazer a confusão estabelecida pelo naturalismo entre físico e psíquico. Este não é o conjunto dos mecanismos cerebrais e nervosos, mas uma região que possui especificidade e peculiaridade; o psíquico é $f e$ nômeno, e não um fato físico, exterior, empírico, governado por relações causais e mecânicas.

0 fenômeno é a consciência, enquanto fluxo temporal de vivências e cuja peculiaridade é a imanência e a capacidade de outorgar significado às coisas.

A fenomenologia é uma descrição da estrutura específica do fenômeno, entendendo por fenômeno o fluxo imanente de vivências que constituem a consciência. A análise da consciência vai muito além da simples análise psicológica, pois o método fenomenológico não procura as condições sob as quais o juízo é verdadeiro e sim qual o significado daquilo que temos na consciência quando julgamos, afirmamos, sonhamos, vivemos. Diante dos fenômenos, o método fenomenológico deve descrevê-los tais como se manifestam, como dados puros e simples da consciência, como significados. Sua tarefa fundamental consiste em torná-los visíveis e aparentes como tais (GILES, 1979).

A fenomenologia é, portanto, para Husserl uma filosofia transcendental e uma ciência rigorosa porque fornece a si própria os seus fundamentos e os de todas as outras ciências, puras ou empíricas.

Husserl considera-se um neocartesiano por concordar com Descartes na necessidade de um método que obrigue a uma reflexão radical sobre os procedimentos adequados para o pensamento filosófico e também por entender, como Descartes, ser o Cogito (subjetividade) a primeira verdade indubitável para começar a pensar corretamente. Deram continuidade à fenomenologia os filósofos Maurice Merleau Ponty, Martin Heidegger e Nicolai Hartmann, entre outros.

As representações construídas racionalmente para apreender e retratar o real são construções teóricas, produzidas por diferentes correntes filosóficas, de acordo com suas visões de mundo. Elas diferem, como procuramos demonstrar e, nestas diferenças, questionase onde estaria a verdade e se há várias verdades.

Em sua acepção mais ampla, o termo ideologia designa aquelas representações construídas racionalmente, ou seja, o conjunto de idéias formuladas para explicar os fenômenos naturais e humanos. Não é hoje, porém, um termo unívoco. Durkheim o utiliza para caracterizar "conhecimentos" obtidos sem neutralidade científica, isto é, sem a separação entre o sujeito e objeto de investigação, regra fundamental que, para o positivismo, garante a objetividade na apreensão da realidade. Neste sentido, Durkheim define como ideológica a atitude subjetiva do cientista, carregada de prénoções e preconceitos inerentes à sociedade onde se insere. 0 conhecimento assim produzido parte das idéias para os fatos quando deve ir dos fatos às idéias (CHIAUI, 1981). 
MARX \& ENGELS (1976) analisando a filosofia alemã, em particular a produção dos Jovens Hegelianos representados por Bruno Bauer, Stirner e Feuerbach, afirmam que a produção de idéias é uma atividade baseada nas formas concretas da existência:

\begin{abstract}
"A produção de idéias, de representações e da consciência está em primeiro lugar direta e intimamente ligada à atividade material e ao comércio material dos homens; é a linguagem da vida real. As representações, o pensamento, o comércio intelectual dos homens surge aqui como emanação direta do seu comportamento material"... "São os homens que produzem as suas representações, as suas idéias etc., mas os homens reais, atuantes e tais como foram condicionados por um determinado desenvolvimento das suas forças produtivas e do modo de relações que lhes corresponde, incluindo até as formas mais amplas que estas possam tomar" (MARX \& ENGELS, 1976).
\end{abstract}

A sociedade, entretanto, não é homogênea; os homens dividem-se em classes que envolvem diferentes práticas sociais. Conseqüentemente em uma sociedade dividida em classes, há diferentes "visões do mundo".

\begin{abstract}
"Os indivíduos que constituem a classe dominante possuem entre outras coisas uma consciência, e é em consequência disso que pensam; na medida em que dominam enquanto classe e determinam uma época histórica em toda sua extensão, é lógico que esses indivíduos dominem em todos os sentidos, que tenham, entre outras, uma posição dominante como seres pensantes, como produtores de idéias que regulamentem a produção e a distribuição dos pensamentos de sua época; as suas idéias são, portanto, as idéias dominantes da sua época" (MARX \& ENGELS, 1976).
\end{abstract}

Neste sentido, para aqueles autores, a ideologia ("stricto sensu") seria uma representação falsa da realidade, pois aparece como generalização do pensamento coletivo, quando realmente expressa as idéias de um grupo dominante.

A questão da possibilidade de o homem apreender a verdade em sua representação do real ficaria, então, assim reduzida: não existe uma verdade absoluta, teórica, isolada. A verdade seria sempre relativa ao contexto onde emerge o objeto do conhecimento e aos critérios utilizados para sua investigação.

Todavia, este trabalho não se ocupará dessa acepção marxista do termo ideologia, abordada em dois trabalhos (GERMANO, 1983; SILVA, 1984) de análise da produção acadêmica da enfermagem profissional brasileira, sendo seu propósito básico, identificar as raízes filosóficas do pensamento referente à área citada.

\section{O CONHECIMENTO EM ENFERMAGEM}

A produção científica em enfermagem, no Brasil, é recente, tendo início com as exigências da carreira universitária em 1963 e intensificando-se, a partir dos anos setenta, com a regulamentação da pós-graduação "stricto sensu".

Dos vários trabalhos que analisam essa produção, destacamos os de ALMEIDA et alii (1984); MENDES \& TREVISAN (1983) e VIEIRA (1980). O primeiro analisa o conhecimento em enfermagem, classificando-o de acordo com determinadas áreas de interesse da pesquisa;o segundo classifica a produção segundo o método indutivo ou dedutivo, procurando determinar as fases atingidas pela investigação na enfermagem. 0 último tem por objetivo identificar a área dos trabalhos, seu marco de referência e sua contribuição para o corpo de conhecimentos da enfermagem.

Nosso propósito aqui é identificar as vinculações dos trabalhos científicos da enfermagem, produzidos no Brasil, às correntes do pensamento filosófico que os embasam, utilizando-nos das "Informações sobre pesquisas e pesquisadores em enfermagem", publicadas pela Associação Brasileira de Enfermagem (1979/84), onde constam os resumos de 285 teses.

Esse embasamento filosófico configura a perspectiva do investigador no enfoque do objeto investigado, perspectiva que determina suas escolhas e rejeições, seu modo de interrogar a realidade, a forma como realiza a investigação; em suma, a sua percepção da relação sujeito-objeto.

Todo investigador necessariamente assume um determinado ponto de vista, do qual tem ou não consciência, embutido nos fundamentos teóricos de seu marco referencial, na construção de suas hipóteses, no conteúdo e forma de seu plano e na relação estabelecida com o fenômeno real (BREILH, 1980).

As revoluções sociais que ocorreram na Europa, principalmente na Inglaterra e França, a partir do século XVII, simultãneas ao rápido desenvolvimento de suas forças produtivas, abriram espaço ao movimento que privilegiava o pensamento racionalizador, a razão predominando sobre o sentimento e a vontade. 0 século XIX marca o triunfo do cientificismo, calcado no êxito das ciências exatas e naturais e traduzido nas aplicações técnicas do mundo industrial. 0 positivismo passa a predominar como fundamentação teórica em todas as áreas (RIBEIRO Jr., 1982), inclusive nas ciências da área médica e de enfermagem.

Embasados neste predomínio do positivismo, elaboramos uma tabela com categorias que correspondem a seus traços característicos, para apreendermos a fundamentação filosófica das dissertações e teses catalogadas pelo Centro de Estudo e Pesquisas em Enfermagem. Um único trabalho tem possibilidade de apresentar vários traços, de tal forma que a somatória de traços é maior que a somatória de trabalhos. 
As categorias listadas foram:

1 - Preocupação em fazer classificações.

2 - Padronização de técnicas, sistematização de procedimentos ou propostas de metodização.

3 - Relações mecânicas entre variáveis (mecanicismo)

4 - Ausência de análises explicativas

5 - Mensuração (privilegiamento do empírico)

6 - Utilização de testes estatísticos, desvio padrão, índices e escalas de mensuração.

7 - Concepção naturalista da doença.

8 - Linguagem matemática

9 - Formulação de hipóteses.

A concepção positivista concebe a prática como mera técnica que amplia automaticamente regras, e princípios vindos da teoria. "A prática não é ação propriamente dita, pois não inventa, não cria, não produz situações novas que suscitem o esforço do pensamento para compreendê-las"' (CHAUI, 1981).

"Num assunto qualquer, o espírito positivo leva sempre a estabelecer exata harmonia elementar, entre as idéias da existência e as idéias de movimento, donde resulta mais especialmente no que respeita aos corpos vivos, a correlação permanente das idéias de organização com as idéias de vida, e, em seguida, graças a uma últıma especialização peculiar ao organismo social, a solidariedade contínua das idéias de ordem com as idéias de progresso. Para a nova filosofia, a ordem constitui sem cessar a condição fundamental do progresso e, reciprocamente, o progresso vem a ser a meta necessária da ordem; como no mecanismo animal, o equilíbrio e a progressão são mutuamente indispensáveis, a título de fundamento ou destinação (COMTE, 1978).

$\mathrm{Na}$ investigação empírica realizada, percebemos durante a leitura dos resumos que, em vários deles, a preocupação em classificar, derivava para uma necessidade de estabelecer normas que já se encontrava antecipadamente, na exposição do problema. Modificamos, então, o enunciado da primeira categoria, ficando assim formulado:

1 - Preocupação prévia em estabelecer normas.

Em decorrência deste traço surge freqüentemente um outro: a preocupação em padronizar técnicas, elaborar programas educacionais, de treinamento e orientação a ocupacionais e a clientes assim como a respectiva avaliação quando introduzidos na assistência de enfermagem.

Outro traço positivista é a busca de relação imediata de causalidade entre dois fatos dados, isto é, dois fatos que têm existência objetiva comprovada empiricamente. A forma privilegiada para esse tipo de verificação é a experimentação, quando existe a possibilidade de se reproduzirem artificialmente os fenômenos estudados, em situações nas quais todas as variáveis intervenientes estão sob o controle do observador. Quando os objetos de estudo não são passíveis de manipulação experimental, recorre-se à comparação, ou experimentação indireta (DURKHEIM, 1966). Isto ocorre com fenõmenos sociais e, por extensão, na enfermagem, pelas particularidades de seu objeto. Dada a complexidade dos fenõmenos que estuda, utiliza o método das variações concomitantes, onde o simples paralelismo estabelecido entre os valores pelos quais passam dois fenõmenos, desde que observados em número suficiente de casos, bastante variados, é prova de que existe entre eles uma relação. Para comprovar esta relação são utilizados procedimentos estatísticos, através de testes de probabilidades.

0 positivismo afirma que a ciência consiste no estudo dos fatos, percebidos pelos sentidos exteriores e suas relações. Não questiona as causas (essência) e as origens das coisas. As leis consistem nas relações constantes que existem entre os fenõmenos, conforme pode ser observado na frase de Comte, abaixo, ao criticar o pensamento metafísico.

"Vemos, pelo que precede, que o caráter fun-
damental da filosofia positiva é tomar todos os
fenômenos como sujeitos a leis naturais inva-
riáveis, cuja descoberta precisa e cuja redução
ao menor número possível constituem o obje-
tivo de todos os nossos esforços, considerado
como absolutamente inacessivel e vazia de sen-
tido para nós a investigação das chamadas cau-
sas, sejam primeiras, sejam finais".

0 positivismo estabelece como premissa essencial a redução do social ao material, isto é, adota e incorpora a fundamentação teórica das ciências naturais para estudar o social, entendendo-o como regido por leis naturais invariáveis e independentes da vontade humana. Na área da saúde, reduz as relações sociais e as condições de existência a variáveis biológicas: idade, sexo, cor; ambientais: condições de moradia, saneamento, ou sócio-econômicas: escolaridade, renda "per capita". Desta forma passam a ser mensuráveis quantitativamente em suas variações, daí a denominaremse variáveis. Equacionadas, tornam-se passíveis de análises estatísticas.

Quanto ao neopositivismo, caracteriza-se, entre outros aspectos pela introdução da lógica matemática como instrumento de análise da linguagem humana.

"Partindo da evidência de que os conhecimen-
tos científicos se objetivam ao serem expres-
sos numa dada linguagem, o Neopositivismo
defendeu que um discurso encerra realmente
conhecimento quando e na medida em que é
logicamente consistente e se refere a elemen-
tos empiricamente constatáveis"...
"A ciência é conhecimento que combina o ra-
ciocínio lógico-matemático (que garante a coe- 
rência e a precisão do pensamento) com a experiência sensorial sistematicamente planejada e avaliada (que permite saber se às idéias lhes correspondem ou não algo real).

Essa combinação se concretiza na formulação de hipóteses e teorias que conduzam a estabelececer as leis que governam os fenômenos" (CUPANI, 1966).

A linguagem matemática foi incluída em nossa listagem a fim de verificarmos sua presença na produção acadêmica da enfermagem.

\section{ANÁLISE DOS RESULTADOS}

$\mathrm{Na}$ Tabela 1, apresentamos os resultados encontrados, com as porcentagens calculadas sobre o total de cada volume. Isto porque, o número de resumos não é constante para todos os volumes: o primeiro e o segundo contêm 60; o terceiro, 88 e o quarto 77.

A "padronização de técnicas, sistematização de procedimentos ou propostas de metodização" inclinamse para um aumento nos dois últimos volumes, o mesmo acontecendo com a "formulação de hipóteses". Os outros traços permanecem em proporçôes relativamente constantes nos quatro volumes. A "ausência de análises explicativas" e a "mensuração, privilegiando o empírico", são as categorias que, por sua alta freqüência (acima de $90 \%$ ), vinculam a produção da enferma- gem ao positivismo, de uma maneira genérica. Esta mensuração, contudo, não é muito elaborada pois, no conjunto dos resumos analisados, apenas cerca de $23 \%$ deles utilizam testes estatísticos, desvio padrão, índices e escalas de mensuração, procedimentos que envolvem uma sofisticação maior no tratamento dos dados. 0 que constatamos, conseqüentemente, nos referidos resumos, foi a tendência ao privilegiamento dos indicadores empíricos mais facilmente quantificáveis, transformando-se a complexidade sensível do paciente em problemas enumeráveis ou opiniões verbais codificadas e mensuradas quantitativamente.

Encontramos uma pequena freqüência da concepção naturalista da doença, ( $4,2 \%$ do total) e apenas um trabalho $(0,35 \%)$ foi caracterizado como neopositivista por apresentar uma linguagem matemática.

Dos resumos analisados, setenta e quatro (25\%) apresentaram uma preocupação prévia em estabelecer normas.

"Quando uma nova ordem de fenômenos se torna objeto de ciência, tais fenômenos já se encontram representados no espírito não apenas por meio de imagens sensíveis, mas também por certos conceitos grosseiramente formados"... "O homem não pode viver entre as coisas sem formular idéias a respeito delas, e regula sua conduta de acordo com tais idéias. Mas, devido a estarem as noções mais próximas de nós e mais ao nosso alcance do que as reali-

TABELA 1 - Traços do positivismo apresentados pelos resumos das teses na área de enfermagem.*

\begin{tabular}{|c|c|c|c|c|c|c|c|c|c|c|}
\hline \multirow[t]{2}{*}{ TRAÇOS DO POSITIVISMO } & \multicolumn{2}{|c|}{$\begin{array}{l}\text { Volume I - } 1979 \\
60 \text { resumos }\end{array}$} & \multicolumn{2}{|c|}{$\begin{array}{l}\text { Volume II - } 1980 \\
60 \text { resumos }\end{array}$} & \multicolumn{2}{|c|}{$\begin{array}{l}\text { Volume III - } 1983 \\
88 \text { resumos }\end{array}$} & \multicolumn{2}{|c|}{$\begin{array}{l}\text { Volume IV - } 1984 \\
77 \text { resumos }\end{array}$} & \multicolumn{2}{|c|}{$\begin{array}{c}\text { TOTAL } \\
285 \text { resumos }\end{array}$} \\
\hline & No & $\%$ & No & $\%$ & No & $\%$ & No & $\%$ & No & $\%$ \\
\hline Preocupação prévia em estabelecer normas & 16 & 26,6 & 15 & 25,0 & 23 & 26,1 & 20 & 25,9 & 74 & 25,9 \\
\hline $\begin{array}{l}\text { Padronização de técnicas, sistematização de } \\
\text { procedimentos ou propostas de metodização }\end{array}$ & 9 & 15,0 & 4 & 6,6 & 28 & 31,8 & 22 & 28,5 & 63 & 22,1 \\
\hline $\begin{array}{l}\text { Relaçōes mecânicas entre variáveis (mecani- } \\
\text { cismo) }\end{array}$ & 37 & 61,6 & 41 & 68,3 & 58 & 65,9 & 47 & 61,0 & 183 & 64,2 \\
\hline Ausência de análises explicativas & 52 & 86,6 & 55 & 91,6 & 87 & 98,8 & 73 & 94,8 & 267 & 93,6 \\
\hline Mensuração (privilegiamento do empírico) & 58 & 96,6 & 58 & 96,6 & 87 & 98,8 & 76 & 98,7 & 279 & 97,8 \\
\hline $\begin{array}{l}\text { Utilização de testes estatísticos, desvio pa- } \\
\text { drão, índices e escalas de mensuração }\end{array}$ & 14 & 23,3 & 14 & 23,3 & 20 & 22,7 & 18 & 23,3 & 66 & 23,1 \\
\hline Concepção naturalista da doença & 4 & 6,6 & 4 & 6,6 & 4 & 4,5 & - & - & 12 & 4,2 \\
\hline Linguagem matemática & - & - & 1 & 1,6 & - & - & - & - & 1 & 0,3 \\
\hline Formulação de hipóteses & 10 & 16,6 & 20 & 33,3 & 45 & 51,1 & 43 & 55,8 & 108 & 37,8 \\
\hline
\end{tabular}

* As porcentagens de cada coluna foram calculadas sobre o total de cada volume. 
dades a que correspondem, tendemos naturalmente para substituir por elas estas últimas, transformando-as na própria matéria de nossas especulações. Em lugar de observar as coisas, descrevê-las, compará-las, contentamo-nos então em tomar consciência de nossas idéias, analisá-las, combiná-las. Em lugar de ciência das realidades, nada mais fazemos do que análise ideológica (DURKHEIM, 1966) (grifo nosso).

Percebemos, naqueles trabalhos, que o investigador já traz, preconcebida, a idéia da enfermagem, pautada em procedimentos regulares, sistematizados, rotinizados para trazer maiores benefícios ao cliente e ao serviço, buscando, então, através da pesquisa, a confirmação de suas suposições. É construída uma assistência de enfermagem idealizada, através da orientações específicas a diversas categorias de clientes agrupados como cardíacos crônicos, gestantes, cirúrgicos no pré e pós operatório; elaboram-se técnicas de assepsia; programam-se cursos de treinamento para pessoal de enfermagem confrontados depois com a assistência existente, quase sempre, assistemática. Na maioria das vezes, conclui-se que a regulamentação traz melhores resultados. Esses trabalhos são ideológicos, no sentido em que DURKHEIM (1966) emprega o termo, por utilizarem tal procedimento.

Quanto a ausência de análises explicativas, gostaríamos de chamar a atenção para o sentido da proposição Comteana. Esta pretendia opor-se à metafísica que, através de construções pretensamente racionais, levava a explicação dos fenõmenos para a esfera do supra-sensível, do inacessível à observação. Comte propõe, então, a renúncia ao conhecimento do absoluto, das causas últimas, passando a dirigir as forças intelectuais para a compreensão das leis e das relações que se podem constatar entre os fenômenos, por meio da observação e dos instrumentos teóricos, o que não exclui análises objetivas dos dados empíricos coletados. A enfermagem, presa a esse postulado, contentase em relatar os fatos, transformados em variáveis $\mathrm{e}$ descrever suas associações, omitindo ou limitando as análises explicativas.

A concomitãncia entre variáveis pode resultar
"Não do fato de um fenômeno ser causa do ou- tro, mas sim de serem ambos efeitos de uma mesma causa, ou ainda de existir entre eles um terceiro fenõmeno intercalado e que passou despercebido o qual é ef eito do primeiro e cau- sa do segundo. Os resultados aos quais esta cor- rente filosófica conduz necessitam, pois, de in- terpretação" (DURKHEIM, 1966).

É interessante, portanto, que a enfermagem aprofunde e aperfeiçoe suas análises avançando na interpretação, conforme o embasamento científico que adota.

Alguns trabalhos mais recentes, ainda não arrola- dos nos catálogos do Centro de Estudos e Pesquisas em Enfermagem, acham-se vinculados a outras perspectivas filosóficas. Procurando apreender o saber e a prática da enfermagem como históricos e articulados a formações sociais concretas, foram produzidas, em 1984, teses que se fundamentam no materialismo histórico (ALMEIDA, 1984; GERMANO, 1983; SILVA, 1984), estão em fase final de elaboração outras, que seguem a vertente fenomenológica. Estas alternativas teóricometodológicas, ao apresentarem diferentes "visões de mundo" dos investigadores, só poderão beneficiar a enfermagem, enriquecendo o conhecimento sobre o seu objeto de estudo e sobre a sua prática.

Concluindo, identificamos uma influência marcante do positivismo nas dissertações e teses produzidas, no Brasil, pelos enfermeiros. Assinalamos também a tendência emergente de propostas alternativas, que buscam fundamentação teórica em outras fontes, como, por exemplo, na dialética e na fenomenologia.

\section{REFERÊNCIAS BIBLIOGRÁFICAS}

1. ALMEIDA, M.C.P. Estudo do saber de Enfermagem e sua dimensão prática. Rio de Janeiro, Escola Nacional de Saúde Pública da Fundação Oswaldo Cruz, 1984. Tese.

2. ALMEIDA, M.C.P. et alii. A produção do conhecimento na pósgraduação em Enfermagem no Brasil. In: CONGRESSO BRASILEIRO DE ENFERMAGEM, 33. Anais... Manaus, Associação Brasileira de Enfermagem, Ago. 1981.

3. ASSOCIAÇÃO BRASILEIRA DE ENFERMAGEM. Centro de Estudos e Pesquisas em Enfermagem. Informações sobre pesquisas e pesquisadores em Enfermagem. Ribeirão Preto, 1979/80/83/84. $4 \mathrm{v}$.

4. BREILH, Jaime. Epidemiologia: economia, medicina y politica. Santo Domingo, Secretaria de Estado de Salud Publica y Asistencia Social, 1980.

5. BUNGE, Mário. Epistemologia: Curso de atualização. Trad. de Cláudio Navarra São Paulo, T.A. Queiróz Ed. da Universidade de São Paulo, 1980.

6. CHAUI, Marilena S. O que é ideologia. 3. ed. São Paulo, Brasiliense, 1981.

7. COMTE, August. Discurso sobre o espírito positivo, 2a. parte $\S \mathrm{X}$ Trad. de José Arthur Giannotti e Miguel Lemos. Os pensadores. São Paulo: Abril Cultural, 1978.

8. Curso de Filosofia Positiva, Primeira lição. §IV. Traduções de José Arthur Giannotti e Miguel Lemos. Os pensadores. São Paulo, Abril Cultural, 1978

9. CORBISIER, Roland. Hegel: Textos escolhidos. Rio de Janeiro, Civilização Brasileira, 1981.

10. CUPANI, Alberto Oscar. Positivismo, neo-positivismo e funcionalismo. In: SEMINÁRIO NACIONAL DE PESQUISA EM ENFERMAGEM, 3, Anais... Florianópolis, Ed. UFSC, 1984.

11. DURKHEIM, Emile. As regras do método sociológico. Trad. Maria Isaura Pereira de Queiróz, São Paulo, Nacional, 1966.

12. GARAUDY, Roger. Karl Marx. Rio de Janeiro. Jahar, 1967.

13. GARCIA, Juan Cesar. Medicina e Sociedade: As correntes do pensamento no campo da saúde. In: NUNES.Everardo Duarte. MedicinaSocial:as pectos históricos e teóricos. São Paulo, Global Ed., 1983.

14. GERMANO, Raimunda Medeiros. Educação e ideologia da En fermagem no Brasil. São Paulo, Cortez, 1983.

15. GILES, Thomas Ransom. Introdução à filosofia. São Paulo, EPU EDUSP, 1979. 
16. HUSSERL, Edmund. Investigações lógicas: sexta investigação: elementos de uma elucidação fenomenológica do conhecimento. Trad. Zeljso Loparic e Andréa Maria Altino de Campos Loparic. São Paulo, Abril Cultural, 1980.

17. LEFEBVRE, Henri. Lógica formal lógica dialética. Trad. Carlos Nelson Coutinho. 3. ed. Rio de Janeiro, Civilização Brasileira, 1983.

18. MARX, Karl \& ENGELS, Friedrich. $A$ ideologia alemã. Trad. Conceição Jardim e Eduardo Lucio Nogueira. Brasil, São Paulo, Ed. presença e Livr. Martins Fontes, 1976.

19. MENDES, I.A.C. \& TREVISAN, M.A. Acerca da utilização do método científico nas pesquisas de Enfermagem. Revista Brasileira de Enfermagem, Brasilia 36(1): 13-9, Jan./mar. 1983.

20. OLIVEIRA, A.S. et alii. Introdução ao pensamento filosófico São Paulo, Ed. Loyola. 1981
21. RIBEIRO Jr. João. O que é positivismo. São Paulo, Brasiliense, 1982.

22. SANTOS, Irineu Ribeiro dos. Teoria do conhecimento e pesquisa social. In: SEMINÁRIO NACIONAL DE PESQUISAS EM ENFERMAGEM, 3, Anais... Florianópolis, ED. UFSC, 1984. p. 33-34.

23. SILVA, Franklin Leopoldo. Teorias do conhecimento. In: CHAUI, Marilena et alii Primeira filosofia. Lições introdutórias. São Paulo, Brasiliense, 1980.

24. SILVA, Graciette Borges. A Enf ermagem profissional brasileira: análise crítica. São Paulo, USP. Faculdade de Filosofia, Letras e Ciências Humanas, Departamento de Ciências Sociais, São Paulo, 1984.

25. VIEIRA, Therezinha Teixeira. Produção científica em Enfermagem no Brasil: 1960-1979. UFBA, Escola de Enfermagem, 1980. Tese de dout. 